\title{
Working Party to Discuss Nomenclature based on Gestational Age and Birthweight
}

On the evening of 7 April 1970 an informal Working Party, $\star$ consisting of obstetricians and paediatricians from 13 European countries, who were attending the Second European Congress of Perinatal Medicine, met and (after discussion) agreed to make the following suggestions:

(a) That there is a need to define the important groups of babies who present special clinical differences and have an increased perinatal mortality, in simple words which straightforwardly reflect what can be measured, namely birthweight and gestational age (thus excluding all words incorporating 'maturity', which cannot be measured as applied to a whole individual).

(b) That this should make it possible to apply to the intrauterine phase of growth the same concepts as have long been applied to the study and definition of growth after birth.

(c) That the essential parameter is the gestational age: calculated from the menstrual dates (and so perhaps better called menstrual age). Where reliable menstrual information is not available, and there is information about the date of ovulation, this can be used, by adding 14 days, to calculate the gestational age. This should then ideally be expressed in days, but if weeks are preferred they should be 'completed weeks' (so that 40 weeks $=280-286$ days): in presenting tables and graphs, both the days and the corresponding weeks

^G. A. Neligan, Chairman (U.K.), A. Ballabriga (Spain), H. Beutnagel (Germany), G. Bucci (Italy), P. M. Dunn (U.K.), H. Ewerbeck (Germany), B. Friis-Hansen (Denmark), D. Gairdner (U.K.), J. Gentz (Sweden), P. O. Hubinot (Belgium), P. Karlberg (Sweden,) G. J. Kloosterman (Holland), F. Kubli (Switzerland), A. A. Minowski (France), L. S. Prod'hom (Switzerland), G. Rooth (Sweden), E. Saling (Germany), C. Sureau (France), T. Valaes (Greece), J. Horsky (Czechoslovakia), and P. J. Huntingford (U.K.). should be stated. If no information is available it was not felt possible in the present state of knowledge to recommend any of the more technical methods of estimating the gestational age for general use.

(d) If it is considered useful (because of difficulties in mortality and morbidity) to group babies in terms of gestational age, the three groups and definitions suggested are:-

(i) Pre-term: less than 259 days (37 weeks).

(ii) Term: 259-293 days (37-41 weeks).

(iii) Post-term: 294 days (42 weeks) or more. There was a considerable body of feeling in favour of placing the limit between pre-term and term 7 days ( 1 week) later, but the arguments in favour of this were not thought to outweigh the fact that 259 days is the official WHO recommendation (Technical Report Series, No. 25, 1950).

(e) That birthweight is of some practical value in itself and when it is the only information available horizontal, dividing lines of the traditional type may be useful, e.g. 2500 g. or less = 'low birthweight', and subdivision by $500 \mathrm{~g}$. intervals may also be useful within this low birthweight group. Separate recording of babies with a birthweight of $1000 \mathrm{~g}$. or less is in any case useful when making statistical comparisons.

$(f)$ The usefulness of birthweight is much increased by relating it to the gestational age, and comparing the results with the known distribution in a defined population (e.g. a centile chart relating birthweight to gestational age, preferably sex-specific and based on the population from which the clinical material is drawn-but otherwise upon the best data available for purposes of comparison). The birthweight can then be expressed in appropriate phases-e.g. 'below 5th centile for boys, Aberdeen 1968 (or 'light-for-dates')'. 